\title{
Biomarker analysis of the phase 3 TORCH trial for first line erlotinib versus chemotherapy in advanced non-small cell lung cancer patients
}

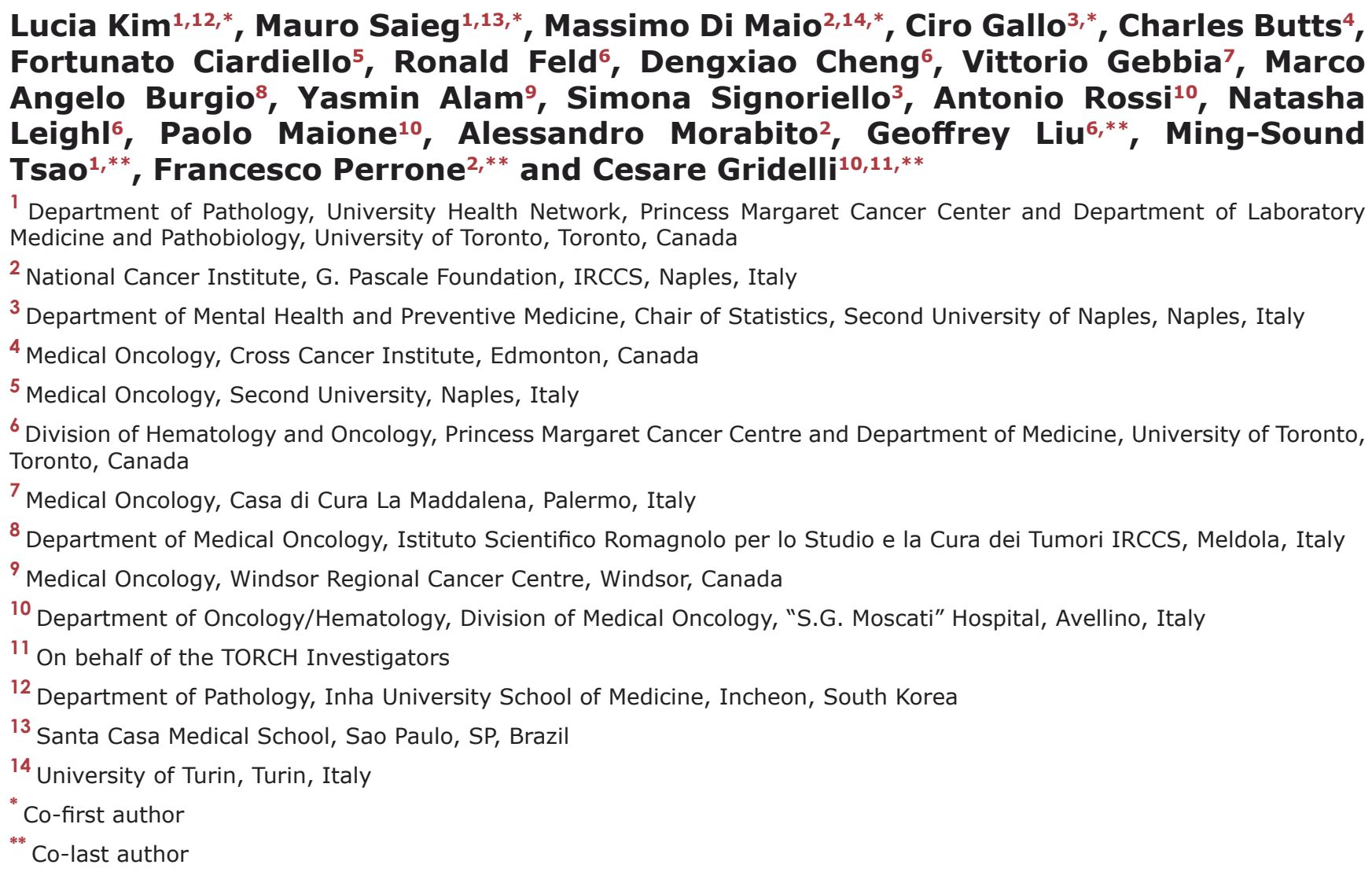

Correspondence to: Cesare Gridelli, email: cgridelli@libero.it

Keywords: NSCLC, EGFR TKI, biomarker analysis, predictive factors, prognostic factors

Received: November 09, $2016 \quad$ Accepted: February 01,2017 Published: February 25, 2017

Copyright: Kim et al. This is an open-access article distributed under the terms of the Creative Commons Attribution License 3.0 (CC BY 3.0), which permits unrestricted use, distribution, and reproduction in any medium, provided the original author and source are credited.

\section{ABSTRACT}

Background: The TORCH phase III trial compared the efficacy of first-line erlotinib followed by chemotherapy at progression (experimental arm) with the reverse sequence (standard arm) in unselected advanced non-small cell lung cancer (NSCLC) patients. Here we report biomarker analyses.

Methods: EGFR and KRAS mutation, expression of EGFR family members and of CMET and PTEN and EGFR and ABCG2 germline polymorphisms were tested on tumor tissue or blood samples to either confirm previously proposed predictive role or describe it in an explorative setting. Progression-free survival (PFS) was the primary end-point, overall survival, response rate and side effects (diarrhoea and skin toxicity) were secondary end-points. Interactions between biomarkers and treatment were studied with multivariable models (either Cox model or logistic regression). Statistical analyses accounted for multiple comparisons.

Results: At least one biomarker was assessed in 324 out of 760 patients in the TORCH study. EGFR mutation was more common in female $(P=\mathbf{0 . 0 0 0 1})$, East Asians 


\begin{abstract}
$(P<0.0001)$ and never smoker $(P<0.0001)$ patients; low MET protein expression by IHC (H-score $<200)$ was more frequent in squamous $(P<0.00009)$ and ABCG2 C/A or A/A polymorphism was more frequent among East-Asian patients $(P=0.0003)$. A significant interaction was found for EGFR mutation in PFS and response rate analyses while no predictive effect on OS was found for any biomarker. No biomarker tested was prognostic for PFS and OS. No polymorphism was significantly associated with skin toxicity or diarrhea.

Conclusion: In the present study, beyond the known role of EGFR mutation, no other biomarker has predictive or prognostic role.
\end{abstract}

\section{INTRODUCTION}

The discovery of oncogenic mutations in the tyrosine kinase (TK) domain of the epidermal growth factor receptor $(E G F R)$ gene, and sensitivity of mutant lung cancers to EGFR-TK inhibitors (TKIs), have revolutionized the treatment of advanced NSCLC. Erlotinib, one of the first generation EGFR-TKIs, has become a standard first line drug for patients with $E G F R$ mutant lung cancers.[1] However, only $60-80 \%$ of NSCLC patients with EGFR mutant tumour respond to EGFRTKI therapy,[2-5] while a small proportion of patients with $E G F R$ wild-type tumors may also benefit from this class of drugs.[6, 7] Primary resistance to EGFR-TKIs has been attributed to various factors, including $E G F R$ exon 20 insertion mutations. [8, 9] Patients whose tumors harbor $K R A S$ mutation are rarely responsive to EGFRTKIs and KRAS mutation might serve as a predictor of resistance to EGFR-TKIs.[10, 11] Activation of alternative signaling pathways including mutations in BRAF, PIK3CA and loss of PTEN have also been implicated as resistance mechanisms in preclinical studies.[12, 13] In addition, germline polymorphisms involving the promoter and intron 1 transcription enhancer regions of the EGFR gene and the $A B C G 2$ multidrug transporter gene have also been reported as modifiers of response to EGFR-TKI therapy. [14-16]

The TORCH (Tarceva OR CHemotherapy) trial was an Italian-Canadian multicenter, open-label, randomized phase III trial comparing first line erlotinib followed by chemotherapy (cisplatin-gemcitabine) at progression, with the reverse standard sequence of first-line chemotherapy followed by erlotinib, in unselected advanced stage IIIB and IV, predominantly Caucasian, NSCLC patients.[17] The study was terminated early due to inferiority of the experimental arm (erlotinib first) in terms of overall survival (OS). In this manuscript, we summarize the results of confirmatory and exploratory analyses of the impact of biomarkers on clinical outcomes in this trial including $E G F R$ gene copy number gains, KRAS mutations, immunohistochemical expression of EGFR family members, cMET and PTEN, and EGFR and $A B C G 2$ germline polymorphisms, in addition to $E G F R$ mutations that have already been partially reported.[17]

\section{RESULTS}

Details of patients' flow and samples available for each biomarker are reported in Supplementary Figure S2. 556 patients consented to biomarker studies and at least one biomarker was tested for $324(42.6 \%)$ patients (study population). Baseline characteristics of the biomarker population were comparable to both the population of patients $(N=673)$ enrolled in centers that provided at least one sample and the whole trial patient population $(N=$ 760) (Supplementary Table S2).

Distribution of biomarkers categories is reported in Table 1. All biomarkers were balanced between treatment arms. Due to low prevalence or absence of positive cases, HER2 and HER3 were excluded from further analyses.

Associations between each biomarker and baseline patients characteristics are described in Supplementary Tables S3 to S13. According to the predefined 0.001 threshold for statistical significance, EGFR mutation was significantly more common in female $(p=0.0001)$, East Asians $(P<0.0001)$ and never smoker $(P<0.0001)$ patients; low MET protein expression by IHC (H-score < 200 ) was more frequent in case of squamous carcinoma $(P=0.00009)$ and ABCG2 C/A or A/A polymorphism was more frequent among East-Asian patients $(P=0.0003)$.

Pairwise association between biomarkers is reported in Supplementary Table S14. No association was significant at the predefined level of 0.001 , with the exception of the obvious one between the two scoring systems for MET protein expression by IHC.

The modifying effects of biomarkers on PFS, OS and response to first treatment are provided in Figures 1 to 3. A significant interaction was only found for $E G F R$ mutation in PFS (Figure 1) and response rate analyses (Figure 3) while no predictive effect on OS was found for any biomarker (Figure 2) at the predefined BonferroniHolm sequential significance levels.

In an exploratory unplanned analysis of patients with non-mutated $E G F R$ or $E G F R$ mutation unknown status, ABCG2 polymorphism had a significant $(P=$ 0.003 ) interaction with treatment effect on PFS (HR for erlotinib vs chemotherapy was $0.62,95 \%$ CI $0.28-1.34$ among $\mathrm{A} / \mathrm{C}$ or $\mathrm{A} / \mathrm{A}$ and $2.07,95 \% \mathrm{CI} 1.54-2.80$ among C/C ABCG2 polymorphisms). Further, adjustment for the Asian ethnicity, which was significantly more common in 
the $A / C$ or $A / A$ arm when compared to the $C / C$ arm, led to similar results.

None of the tested biomarkers was prognostic for PFS and OS at the pre-defined significance level of 0.01 (Table 2).

None of the polymorphisms evaluated were significantly associated with skin toxicity or diarrhea (Supplementary Table S15).

\section{DISCUSSION}

As an ancillary analysis of the TORCH trial, we explored potential biomarkers for predicting the response or resistance to the EGFR-TKIs compared with chemotherapy. We assessed both biomarker-bytreatment interactions and prognostic value of the proposed biomarkers. Follow-up data were mature and a conservative statistical analysis plan was applied accounting for multiplicity of comparisons and reducing the expected inflation of false positive results. As a major limitation, however, biomarkers' evaluation was not mandatory in the trial and was actually performed only in $43 \%$ of the patients; nonetheless, this rate compares well with other trials in advanced lung cancer where biologic sample collection was not mandatory.

Except for EGFR mutation,[17] we failed to confirm the predictive role of any other biomarker, including high expression of HER2, HER3, cMET and loss of PTEN expression, that were studied due to their potential role in activating bypass survival pathway downstream of EGFR.[18, 19] Among these markers, we found no or very few cases with high expression of HER2 and HER3. Interestingly, the first treatment progression free hazard ratio for high and low cMET expression (H-score $\geq 200$ vs $<200$ ) was 3.04 vs. 1.45 , with borderline interaction $\mathrm{p}$ value of 0.056 . These results confirm that first line chemotherapy is superior to erlotinib irrespective of cMET expression level, however suggesting that any potential activity of erlotinib is significantly less in tumor that express very high level of cMET. Unfortunately, the low number of patients with EGFR mutant tumor exclude us from studying potential role of high MET expression as a potential negative predictive marker in first line EGFR TKI therapy.

The predictive role of EGFR gene copy number as determined by fluorescence in situ hybridization (FISH)

\begin{tabular}{|c|c|c|c|c|c|c|}
\hline & & & \#event & /\#pts & & \\
\hline & $\mathrm{N}$ & & Chemo & Erlotinib & HR $(95 \% \mathrm{Cl})$ & Interaction $\mathrm{P}$ \\
\hline All patients & 760 & & $335 / 380$ & $356 / 380$ & $1.53(1.31-1.77)$ & \\
\hline Biomarker population & 324 & - & $151 / 164$ & $155 / 160$ & $1.49(1.19-1.87)$ & \\
\hline KRAS mutation & & & & & & 0.81 \\
\hline wild-type & 203 & -1 & $90 / 101$ & $99 / 102$ & $1.56(1.17-2.09)$ & \\
\hline mutated & 73 & -1 & $34 / 35$ & $38 / 38$ & $1.70(1.06-2.72)$ & \\
\hline EGFR mutation & & & & & & 0.005 \\
\hline wild-type & 236 & -1 & $106 / 116$ & $118 / 120$ & $2.09(1.60-2.73)$ & \\
\hline mutated & 39 & 1 & $18 / 20$ & $18 / 19$ & $0.60(0.30-1.20)$ & \\
\hline EGFR gene copy & & & & & & 0.44 \\
\hline negative & 94 & -1 & $36 / 41$ & $52 / 53$ & $1.93(1.26-2.97)$ & \\
\hline positive & 102 & -1 & $47 / 54$ & $48 / 48$ & $1.58(1.05-2.38)$ & \\
\hline$\overline{\text { EGFR IHC }}$ & & & & & & 0.26 \\
\hline low & 147 & $\longmapsto !$ & $67 / 76$ & $70 / 71$ & $1.85(1.32-2.61)$ & \\
\hline high & 17 & -1 & $7 / 7$ & $10 / 10$ & $0.89(0.32-2.49)$ & \\
\hline PTEN & & & & & & 0.14 \\
\hline negative & 30 & -1 & $15 / 17$ & $13 / 13$ & $2.67(1.24-5.76)$ & \\
\hline MET-H200 & & & & & & 0.056 \\
\hline low & 85 & $!$ & $36 / 40$ & $44 / 45$ & $1.45(0.93-2.27)$ & \\
\hline high & 69 & 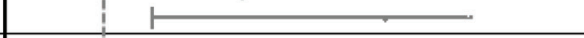 & $33 / 36$ & $33 / 33$ & $3.04(1.79-5.17)$ & \\
\hline MET IHC & & & & & & 0.16 \\
\hline negative & 64 & -1 & $28 / 32$ & $31 / 32$ & $1.44(0.86-2.42)$ & \\
\hline positive & 90 & it & $41 / 44$ & $46 / 46$ & $2.32(1.49-3.60)$ & \\
\hline EGFR-216 & & & & & & 0.55 \\
\hline$G / G$ & 78 & & $34 / 38$ & $39 / 40$ & $1.41(0.89-2.25)$ & \\
\hline $\mathrm{T} /-$ & 162 & 10 & $70 / 79$ & $81 / 83$ & $1.72(1.24-2.38)$ & \\
\hline EGFR-191 & & & & & & 0.66 \\
\hline $\mathrm{c} / \mathrm{C}$ & 195 & & $85 / 95$ & $97 / 100$ & $1.56(1.16-2.09)$ & \\
\hline $\mathrm{C} / \mathrm{A}$ or $\mathrm{A} / \mathrm{A}$ & 45 & -1 & $19 / 22$ & $23 / 23$ & $1.68(0.90-3.13)$ & \\
\hline EGFR CA repeat & & & & & & 0.53 \\
\hline$s / s$ & 74 & & $25 / 29$ & $43 / 45$ & $1.39(0.85-2.30)$ & \\
\hline$S / L$ or $L / L$ & 188 & 4 & $90 / 99$ & $88 / 89$ & $1.62(1.20-2.18)$ & \\
\hline$A B C G 2$ & & & & & & 0.04 \\
\hline $\mathrm{c} / \mathrm{C}$ & 218 & -8 & $93 / 104$ & $111 / 114$ & $1.71(1.30-2.26)$ & \\
\hline$C / A$ or $A / A$ & 39 & 1 & $20 / 22$ & $17 / 17$ & $0.71(0.34-1.47)$ & \\
\hline
\end{tabular}

Figure 1: Forest plot of progression free survival by treatment arm and biomarkers. Hazard ratio $(\mathrm{HR})<1$ means a lower risk of progression or death for patients treated with first-line erlotinib. 
Table 1: Distribution of biomarkers according to treatment arm, within the biomarker population ( $\mathrm{n}=324$ patients with at least one biomarker available)

\begin{tabular}{|c|c|c|c|c|c|}
\hline Biomarker & Category & $\begin{array}{l}\text { Standard } \\
\operatorname{Arm}(\mathbf{G} / \mathbf{C}) \\
(N=164)\end{array}$ & $\begin{array}{l}\text { Experimental } \\
\text { Arm (E) } \\
(N=160)\end{array}$ & $\begin{array}{l}\text { Overall } \\
(N=324)\end{array}$ & $P$ value* \\
\hline \multicolumn{6}{|l|}{ Genomic Testing } \\
\hline \multirow{3}{*}{$K R A S$ mutation } & Wild type & $101(62 \%)$ & $102(64 \%)$ & $203(63 \%)$ & \multirow{3}{*}{0.49} \\
\hline & Mutant & $35(21 \%)$ & $38(24 \%)$ & $73(23 \%)$ & \\
\hline & Unknown & $28(17 \%)$ & $20(12 \%)$ & $48(15 \%)$ & \\
\hline \multirow{3}{*}{$E G F R$ mutation } & Wild type & $1116(71 \%)$ & $120(75 \%)$ & $236(73 \%)$ & \multirow{3}{*}{0.59} \\
\hline & Mutant & $20(12 \%)$ & $19(12 \%)$ & $39(12 \%)$ & \\
\hline & Unknown & $28(17 \%)$ & $21(13 \%)$ & $49(15 \%)$ & \\
\hline \multirow{3}{*}{$E G F R$ gene copy } & Low & $41(25 \%)$ & $53(33 \%)$ & $94(29 \%)$ & \multirow{3}{*}{0.27} \\
\hline & High & $54(33 \%)$ & $48(30 \%)$ & $102(31 \%)$ & \\
\hline & Unknown & $69(42 \%)$ & $59(37 \%)$ & $128(40 \%)$ & \\
\hline \multicolumn{6}{|c|}{ Immunohistochemical Staining } \\
\hline \multirow{3}{*}{ EGFR IHC score } & Low & $76(46 \%)$ & $71(44 \%)$ & $147(45 \%)$ & \multirow{3}{*}{0.71} \\
\hline & High & $7(4 \%)$ & $10(6 \%)$ & $17(5 \%)$ & \\
\hline & Unknown & $81(49 \%)$ & $79(49 \%)$ & $160(49 \%)$ & \\
\hline \multirow{3}{*}{ PTEN } & Negative & $17(10 \%)$ & $13(8 \%)$ & $30(9 \%)$ & \multirow{3}{*}{0.70} \\
\hline & Positive & $57(35 \%)$ & $61(38 \%)$ & $118(36 \%)$ & \\
\hline & Unknown & $90(55 \%)$ & $86(54 \%)$ & $176(54 \%)$ & \\
\hline \multirow{3}{*}{ MET-H200 } & Low & $40(24 \%)$ & $45(28 \%)$ & $85(26 \%)$ & \multirow{3}{*}{0.75} \\
\hline & High & $36(22 \%)$ & $33(21 \%)$ & $69(21 \%)$ & \\
\hline & Unknown & $88(54 \%)$ & $82(51 \%)$ & $170(52 \%)$ & \\
\hline \multirow{3}{*}{ MET-IHC } & Negative & $32(20 \%)$ & $32(20 \%)$ & $64(20 \%)$ & \multirow{3}{*}{0.90} \\
\hline & Positive & $44(27 \%)$ & $46(29 \%)$ & $90(28 \%)$ & \\
\hline & Unknown & $88(54 \%)$ & $82(51 \%)$ & $170(52 \%)$ & \\
\hline \multirow{3}{*}{ HER2 } & Low & $59(36 \%)$ & $56(35 \%)$ & $115(35 \%)$ & \multirow{3}{*}{0.83} \\
\hline & High & $2(1 \%)$ & $1(1 \%)$ & $3(1 \%)$ & \\
\hline & Unknown & $103(63 \%)$ & $103(64 \%)$ & $206(64 \%)$ & \\
\hline \multirow{3}{*}{ HER3 } & Low & $74(45 \%)$ & $70(44 \%)$ & $144(44 \%)$ & \multirow{3}{*}{0.80} \\
\hline & High & 0 & 0 & 0 & \\
\hline & Unknown & $90(55 \%)$ & $90(56 \%)$ & $180(56 \%)$ & \\
\hline \multicolumn{6}{|c|}{ Germline polymorphisms } \\
\hline \multirow{3}{*}{$E G F R-216$} & $G / G$ & $38(23 \%)$ & $40(25 \%)$ & $78(24 \%)$ & \multirow{3}{*}{0.52} \\
\hline & $G / T$ or $T / T$ & $79(48 \%)$ & $83(52 \%)$ & $162(50 \%)$ & \\
\hline & Unknown & $47(29 \%)$ & $37(23 \%)$ & $84(26 \%)$ & \\
\hline \multirow{3}{*}{$E G F R-191$} & $C / C$ & $95(58 \%)$ & $100(62 \%)$ & $195(60 \%)$ & \multirow{3}{*}{0.52} \\
\hline & $C / A$ or $A / A$ & $22(13 \%)$ & $23(14 \%)$ & $45(14 \%)$ & \\
\hline & Unknown & $47(29 \%)$ & $37(23 \%)$ & $84(26 \%)$ & \\
\hline & $\mathrm{S} / \mathrm{S}$ & $29(18 \%)$ & $45(28 \%)$ & $74(23 \%)$ & \\
\hline$E G F R$ CA repeat & $\mathrm{S} / \mathrm{L}$ or $\mathrm{L} / \mathrm{L}$ & $99(60 \%)$ & $89(56 \%)$ & $188(58 \%)$ & 0.06 \\
\hline & Unknown & $36(22 \%)$ & $26(16 \%)$ & $62(19 \%)$ & \\
\hline & $C / C$ & $104(63 \%)$ & $114(71 \%)$ & $218(67 \%)$ & \\
\hline$A B C G 2$ & $C / A$ or $A / A$ & $22(13 \%)$ & $17(11 \%)$ & $39(12 \%)$ & 0.32 \\
\hline & Unknown & $38(23 \%)$ & $29(18 \%)$ & $67(21 \%)$ & \\
\hline
\end{tabular}

*Chi square test, comparing Standard and Experimental Arms; EGFR CA repeat S (short): $\leq 16 \mathrm{CA}$ repeat; L (Long): $\geq 17 \mathrm{CA}$ repeat; Unknowns are due to lack of remaining material available for biomarker assessment. 
is a matter of controversy.[3, 20-22] As high percentages of EGFR mutant NSCLC also demonstrate amplification of the gene, it was postulated that the predictiveness of $E G F R$ high gene copy number could be accounted by the presence of mutation. In fact, in the IPASS patients, EGFR FISH was not predictive in EGFR wild type patients.[23] The results of our analysis in the TORCH patients confirm this finding (Supplementary Figure S3).

Despite suggestions that germline polymorphisms may be associated with erlotinib efficacy, none has consistently been associated with survival or response.[15, 16] In the TORCH trial, we found a significant interaction between the $A B C G 2+421$ polymorphism and PFS. The non significant finding of interaction for OS $(P=0.11)$ may have been favoured by the cross-over design. In this trial, the vast majority of patients likely carried wild type $E G F R$, which is the primary driver of best initial response. In contrast, wild type EGFR produces mostly stable disease responses, and thus it was unlikely that initial response would be differentiated in this population by genetic polymorphisms; indeed we found no relationship between any of the polymorphisms and best initial response to therapy. Two exploratory analyses of $A B C G 2$ +421 were performed. This $A B C G 2$ polymorphism had been evaluated in one other randomized control trial involving erlotinib as the experimental drug but in a different setting: the BR.21 trial of chemo-refractory placebo-controlled metastatic/advanced stage patients found no significantly interaction associations between this polymorphism and the trial arm for any treatment outcomes.[15] The same polymorphisms may affect toxicity.[15, 24] However, in the TORCH trial, we found no significant or even trends in relationship with any of the main toxicities of erlotinib, but small samples sizes limited any firm conclusions.

In conclusion, an extensive exploratory biomarker analysis in TORCH trial failed to identify additional predictive or prognostic biomarkers beyond EGFR mutation in first line erlotinib therapy.

\section{MATERIALS AND METHODS}

The details of the TORCH clinical trial eligibility and conduct have been described previously.[17]

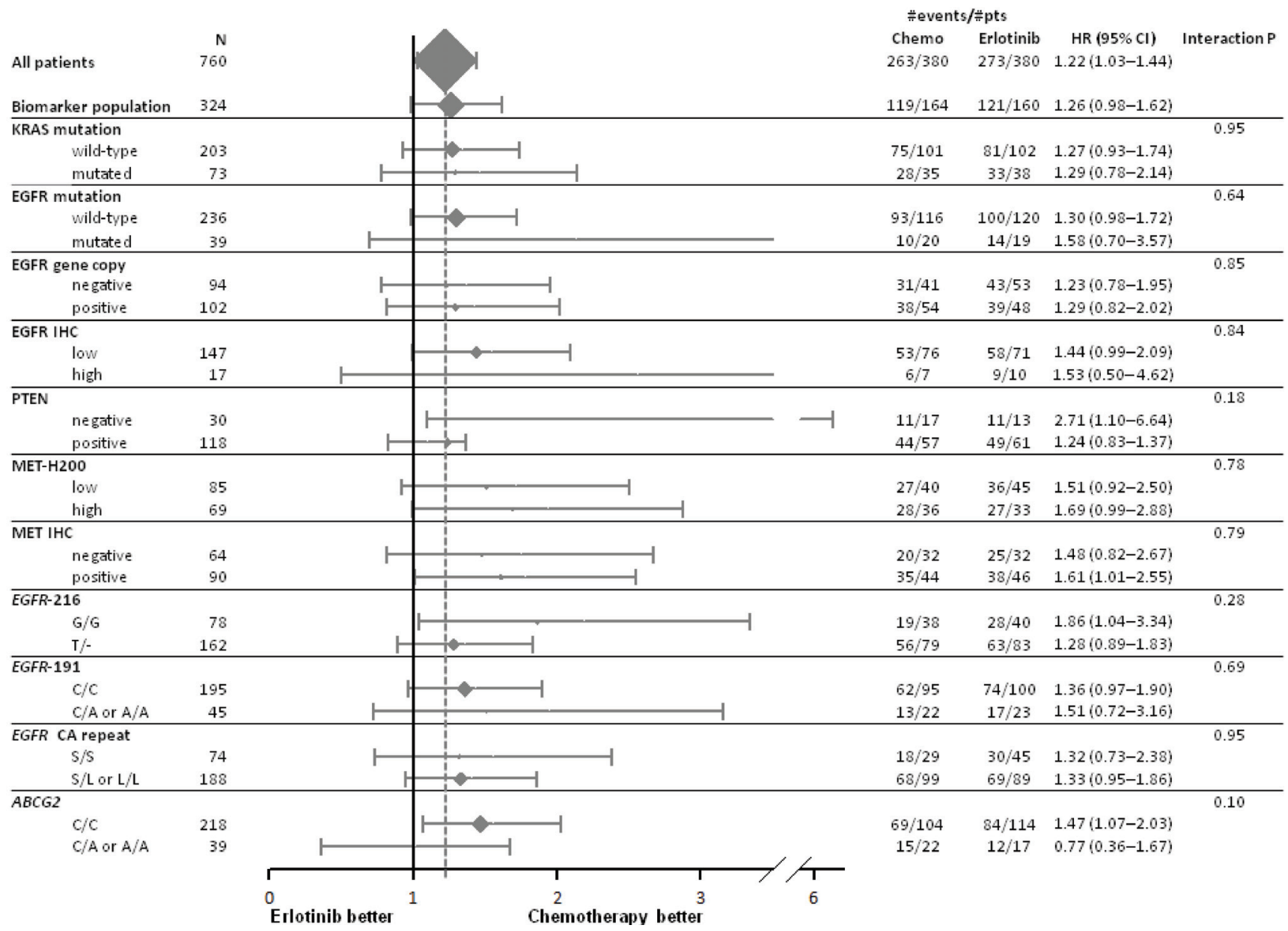

Figure 2: Forest plot of overall survival by treatment arm and biomarkers. Hazard ratio (HR) $<1$ means a lower risk of death for patients treated with first-line erlotinib. 
Formalin fixed paraffin embedded blocks or unstained sections of tumor tissue were collected. Because of limited tissue materials, biomarker analyses were performed in the following priority order: $E G F R$ mutation status, KRAS mutation, EGFR gene copy number (GCN) by fluorescent in situ hybridization (FISH), EGFR, cMET, HER2, HER3 and PTEN protein expression by immunohistochemistry. The remaining material was used for genotyping of EGFR and $A B C G 2$ polymorphisms (when no blood sample or tissue block of normal tissue was available). No prioritization was required for blood sample derived DNA.

All biomarker assays were performed at the Applied Molecular Profiling Laboratory at the Princess Margaret Cancer Centre. All tissue analyses were preceded by a pathology review of the hematoxylin eosin (HE) stained slides to confirm the diagnosis, estimate the tumor cell abundance and mark the tumor areas for macrodissection or FISH scoring. The procedure of the EGFR mutation test and $E G F R / A B C G 2$ polymorphism analysis has been described previously.[15, 17, 25]
EGFR exon 19 deletion and exon 21 L858R mutations were analysed as previously reported.[17] $K R A S$ codon 12 and 13 mutations were analysed using the capilllary sequencing method, with positive or equivocal results confirmed by repeat sequencing. $E G F R$ gene copy number was evaluated by fluorescence in situ hybridization; high and low copy number cases were categorized using the University of Colorado system, as reported previously.[25]

IHC staining was performed using the BenchMark XT autostainer (Ventana, Tucson, AZ). The antibodies, staining conditions and scoring cut-offs used are detailed in Supplementary Table S1. For each marker, the staining intensity (grades 0 to 3 ) and estimated percentage (\%) of tumor cells at each intensity grade were recorded. The $\mathrm{H}$-score was the sum of \% stained tumor cells at each staining intensity. For EGFR, HER2 and HER3, cases were classified as low or high expression, using H-score $<200$ and $\geq 200$, respectively. Two scoring systems were used for cMET: (1) MET-H200 scoring system using H-score $<200$ and $\geq 200$ as above; and (2) the MET

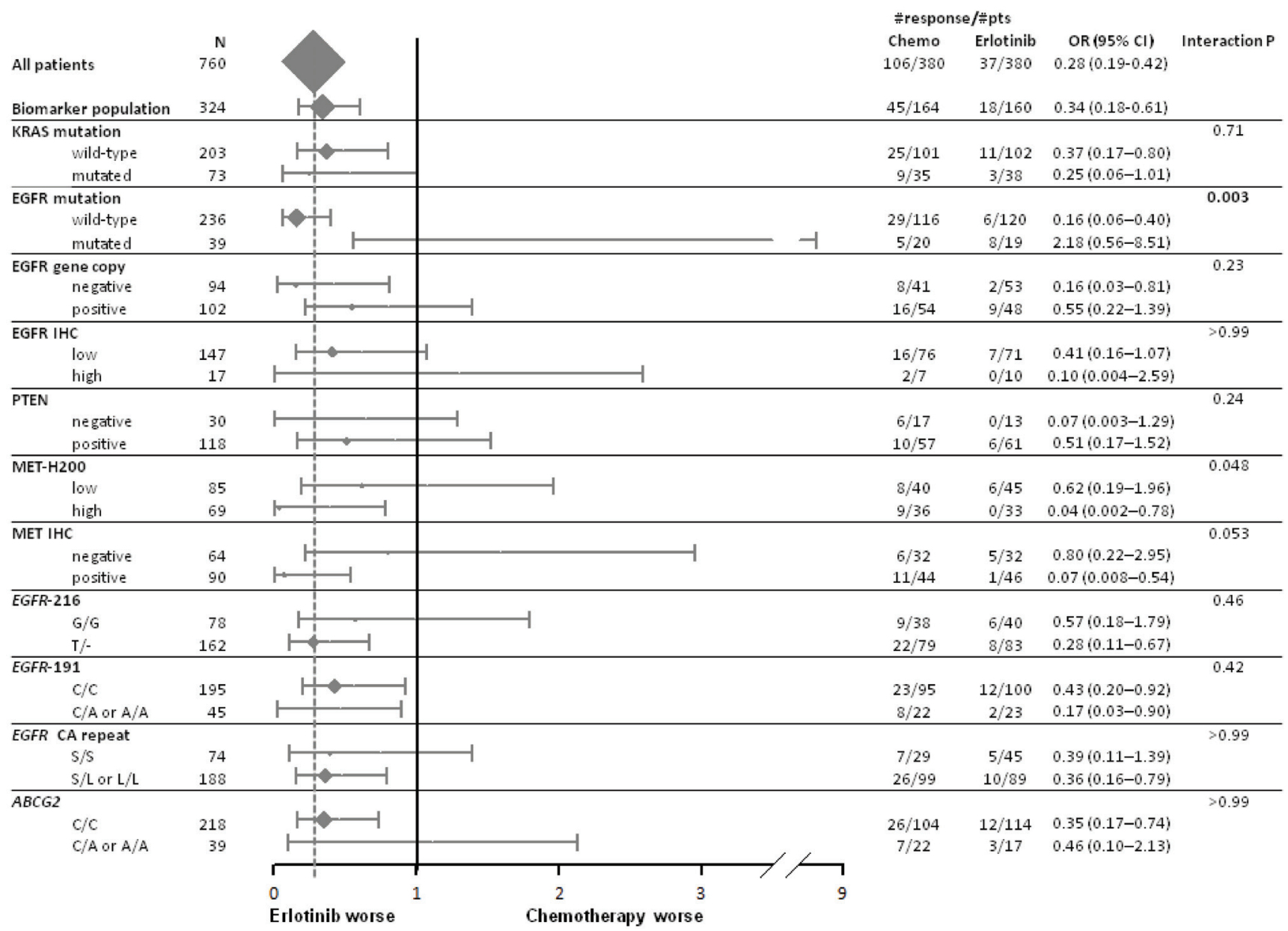

Figure 3: Forest plot of response by treatment arm and biomarkers. Odds ratio $(\mathrm{OR})>1$ means a higher probability of response for patients treated with first-line erlotinib. 
Table 2: Prognostic role of biomarkers with no significant interaction with treatment

\begin{tabular}{|c|c|c|c|c|}
\hline & \multicolumn{2}{|c|}{ Progression-free survival } & \multicolumn{2}{|c|}{ Overall survival } \\
\hline & $\begin{array}{l}\text { Hazard ratio } \\
(95 \% \text { CI })\end{array}$ & $P$ value & $\begin{array}{l}\text { Hazard ratio } \\
(95 \% \text { CI) }\end{array}$ & $P$ value \\
\hline \multicolumn{5}{|l|}{ EGFR gene copy } \\
\hline High vs low & $\begin{array}{l}0.82 \\
(0.61-1.10)\end{array}$ & 0.19 & \begin{tabular}{|l|}
0.77 \\
$(0.56-1.06)$
\end{tabular} & 0.11 \\
\hline \multicolumn{5}{|l|}{ EGFR IHC } \\
\hline High vs low & $\begin{array}{l}1.06 \\
(0.64-1.77) \\
\end{array}$ & 0.82 & \begin{tabular}{|l|}
1.00 \\
$(0.58-1.72)$ \\
\end{tabular} & 0.99 \\
\hline \multicolumn{5}{|l|}{ KRAS mutation } \\
\hline Mutant vs wild type & $\begin{array}{l}1.23 \\
(0.93-1.61)\end{array}$ & 0.14 & \begin{tabular}{|l|}
1.13 \\
$(0.84-1.52)$ \\
\end{tabular} & 0.42 \\
\hline \multicolumn{5}{|l|}{ PTEN } \\
\hline Positive vs negative & $\begin{array}{l}0.99 \\
(0.65-1.51)\end{array}$ & 0.95 & \begin{tabular}{|l|}
1.13 \\
$(0.71-1.81)$ \\
\end{tabular} & 0.61 \\
\hline \multicolumn{5}{|l|}{ MET-H200 } \\
\hline High vs low & $\begin{array}{l}1.39 \\
(0.99-1.95) \\
\end{array}$ & 0.055 & \begin{tabular}{|l|}
1.42 \\
$(0.99-2.05)$ \\
\end{tabular} & 0.059 \\
\hline \multicolumn{5}{|l|}{ MET-IHC } \\
\hline Positive vs negative & $\begin{array}{l}1.50 \\
(1.07-2.10)\end{array}$ & 0.02 & \begin{tabular}{|l|}
1.46 \\
$(1.01-2.13)$ \\
\end{tabular} & 0.047 \\
\hline \multicolumn{5}{|l|}{ EGFR SNP 216} \\
\hline G/G vs T/- & $\begin{array}{l}0.78 \\
(0.59-1.03)\end{array}$ & 0.082 & \begin{tabular}{|l|}
0.67 \\
$(0.48-0.94)$ \\
\end{tabular} & 0.019 \\
\hline \multicolumn{5}{|l|}{ EGFR SNP 191} \\
\hline $\mathrm{C} / \mathrm{C}$ vs $\mathrm{A} /-$ & $\begin{array}{l}1.13 \\
(0.80-1.58)\end{array}$ & 0.49 & $\begin{array}{l}1.19 \\
(0.80-1.78) \\
\end{array}$ & 0.38 \\
\hline \multicolumn{5}{|l|}{$A B C G 2$} \\
\hline $\mathrm{C} / \mathrm{C}$ vs $\mathrm{A} /-$ & $\begin{array}{l}1.10 \\
(0.78-1.57)\end{array}$ & 0.58 & \begin{tabular}{|l|}
1.10 \\
$(0.73-1.66)$ \\
\end{tabular} & 0.66 \\
\hline \multicolumn{5}{|l|}{ EGFR CA repeat } \\
\hline $\mathrm{S} / \mathrm{S}$ vs $\mathrm{L} /-$ & $\begin{array}{l}0.94 \\
(0.71-1.25)\end{array}$ & 0.67 & $\begin{array}{l}0.89 \\
(0.64-1.24)\end{array}$ & 0.48 \\
\hline
\end{tabular}

IHC scoring system that was developed in a previous trial.[26] The latter score was assessed independently by two pathologists (LK and MST) and the final METIHC represents the mean of the two independent scores (Supplementary Figure S1). PTEN IHC was interpreted as negative when there was no staining at all.[27] All interpretation was performed without information on clinical outcome and assigned treatment strategy.

Blood samples were collected using a kit provided by the central laboratory with specific processing and shipment instructions. DNA was isolated using the Qiagen humanDNA kit. Polymorphism analyses for $E G F R$ promoter (-216 $G>T$, rs712829 and $-191 C>A$ rs712830), $E G F R$ intron $1 C A$ repeat polymorphisms and for the $A B C G 2+421 C>A$ (rs2231142) polymorphisms have been described previously. $[15,16]$ In brief, analyses were conducted using direct Sanger sequencing and Taqman polymerase chain reaction (PCR) reaction. For patients without blood samples, analyses were conducted using DNA isolated from FFPE tumor samples used for mutation analyses, as a surrogate material. Our prior work has shown this region to be highly preserved when comparing germline to somatic material from lung cancer, with $>90 \%$ agreement in paired blood-tumor tissue analyses.[15, 16]

The statistical analysis plan is detailed in the Supplementary materials on line. Several biomarkers were evaluated in confirmatory ( $E G F R$ mutation, EGFR gene copy, EGFR IHC, KRAS mutation, polymorphic variants of EGFR (SNP 216, SNP 191, CA repeat) and ABCG2) and exploratory (PTEN, MET.H200, MET IHC, HER2, HER3) analyses. Because of multiplicity of comparisons different significance levels were used according to a predefined step-down Holm-Bonferroni sequential testing procedure.

All efficacy analyses were based on intention-totreat strategy. The primary end-point was progression-free 
survival (PFS) to first treatment, while overall survival (OS) and response rate to first treatment (RR) were secondary end-points.

Both predictive and prognostic roles of biomarkers were evaluated using the appropriate multivariable models.

\section{ACKNOWLEDGMENTS}

M.Tsao is the M. Qasim Choksi Chair in Lung Cancer Translational Research at the Princess Margaret Cancer Centre/University of Toronto.

\section{CONFLICTS OF INTEREST}

M.Tsao and F.Perrone have received research funding from Roche. G.Liu, C.Butts, F.Ciardiello, A.Morabito, F.Perrone and C.Gridelli have received honoraria from AstraZeneca, Boeringher Ingelheim and Roche. A. Rossi has received honoraria from AstraZeneca and Boeringher Ingelheim.

\section{FUNDING}

This work was supported by a research grant from the Hoffmann-LaRoche. L.Kim and M.Saieg were supported by the Terry Fox Foundation Special Training Initiative in Health Research for clinician scientists in molecular Oncologic Pathology at CIHR (STP 53912).

\section{Authors contribution}

All the authors reviewed the manuscript and agreed to submit it. CG, CB, FC. RF, FP and CG represented the Steering Committee. LK, MS, DC, GL and MST produced laboratory data. MDM, CG, SS, GL, MST and FP performed analysis and interpreted data. $\mathrm{CB}, \mathrm{FC}, \mathrm{RF}, \mathrm{VG}$, MAB, YA, AR, NL, PM, AM, CG enrolled and treated patients and provided clinical data.

\section{REFERENCES}

1. Besse B, Adjei A, Baas P, Meldgaard P, Nicolson M, PazAres L, Reck M, Smit EF, Syrigos K, Stahel R, Felip E, Peters S, Panel M, et al. 2nd ESMO Consensus Conference on Lung Cancer: non-small-cell lung cancer first-line/ second and further lines of treatment in advanced disease. Ann Oncol. 2014; 25: 1475-84. doi: 10.1093/annonc/ mdu123.

2. Mitsudomi T, Morita S, Yatabe Y, Negoro S, Okamoto I, Tsurutani J, Seto T, Satouchi M, Tada H, Hirashima T, Asami K, Katakami N, Takada M, et al. Gefitinib versus cisplatin plus docetaxel in patients with non-small-cell lung cancer harbouring mutations of the epidermal growth factor receptor (WJTOG3405): an open label, randomised phase 3 trial. Lancet Oncol. 2010; 11: 121-8. doi: 10.1016/S14702045(09)70364-X.

3. Mok TS, Wu YL, Thongprasert S, Yang CH, Chu DT, Saijo N, Sunpaweravong P, Han B, Margono B, Ichinose Y, Nishiwaki Y, Ohe Y, Yang JJ, et al. Gefitinib or carboplatinpaclitaxel in pulmonary adenocarcinoma. N Engl J Med. 2009; 361: 947-57. doi: 10.1056/NEJMoa0810699.

4. Rosell R, Carcereny E, Gervais R, Vergnenegre A, Massuti B, Felip E, Palmero R, Garcia-Gomez R, Pallares C, Sanchez JM, Porta R, Cobo M, Garrido P, et al. Erlotinib versus standard chemotherapy as first-line treatment for European patients with advanced EGFR mutation-positive non-small-cell lung cancer (EURTAC): a multicentre, openlabel, randomised phase 3 trial. Lancet Oncol. 2012; 13: 239-46. doi: 10.1016/S1470-2045(11)70393-X.

5. Zhou C, Wu YL, Chen G, Feng J, Liu XQ, Wang C, Zhang S, Wang J, Zhou S, Ren S, Lu S, Zhang L, Hu C, et al. Erlotinib versus chemotherapy as first-line treatment for patients with advanced EGFR mutation-positive non-smallcell lung cancer (OPTIMAL, CTONG-0802): a multicentre, open-label, randomised, phase 3 study. Lancet Oncol. 2011; 12: 735-42. doi: 10.1016/S1470-2045(11)70184-X.

6. Shepherd FA, Rodrigues Pereira J, Ciuleanu T, Tan EH, Hirsh V, Thongprasert S, Campos D, Maoleekoonpiroj S, Smylie M, Martins R, van Kooten M, Dediu M, Findlay $\mathrm{B}$, et al. Erlotinib in previously treated non-small-cell lung cancer. N Engl J Med. 2005; 353: 123-32. doi: 10.1056/ NEJMoa050753.

7. Soria JC, Felip E, Cobo M, Lu S, Syrigos K, Lee KH, Goker E, Georgoulias V, Li W, Isla D, Guclu SZ, Morabito A, Min YJ, et al. Afatinib versus erlotinib as second-line treatment of patients with advanced squamous cell carcinoma of the lung (LUX-Lung 8): an open-label randomised controlled phase 3 trial. Lancet Oncol. 2015; 16: 897-907. doi: 10.1016/S1470-2045(15)00006-6.

8. Rosell R, Molina MA, Costa C, Simonetti S, GimenezCapitan A, Bertran-Alamillo J, Mayo C, Moran T, Mendez $\mathrm{P}$, Cardenal F, Isla D, Provencio M, Cobo $\mathrm{M}$, et al. Pretreatment EGFR T790M mutation and BRCA1 mRNA expression in erlotinib-treated advanced non-small-cell lung cancer patients with EGFR mutations. Clin Cancer Res. 2011; 17: 1160-8. doi: 10.1158/1078-0432.CCR-10-2158.

9. Yasuda H, Kobayashi S, Costa DB. EGFR exon 20 insertion mutations in non-small-cell lung cancer: preclinical data and clinical implications. Lancet Oncol. 2012; 13: e23-31. doi: 10.1016/S1470-2045(11)70129-2.

10. Riely GJ, Marks J, Pao W. KRAS mutations in non-small cell lung cancer. Proc Am Thorac Soc. 2009; 6: 201-5. doi: 10.1513/pats.200809-107LC.

11. Zer A, Ding K, Lee SM, Goss GD, Seymour L, Ellis PM, Hackshaw A, Bradbury PA, Han L, O’Callaghan CJ, Tsao MS, Shepherd FA. Pooled Analysis of the Prognostic and Predictive Value of KRAS Mutation Status and Mutation Subtype in Patients with Non-Small Cell Lung Cancer Treated with Epidermal Growth Factor Receptor Tyrosine 
Kinase Inhibitors. J Thorac Oncol. 2016; 11: 312-23. doi: 10.1016/j.jtho.2015.11.010.

12. Janmaat ML, Kruyt FA, Rodriguez JA, Giaccone G. Response to epidermal growth factor receptor inhibitors in non-small cell lung cancer cells: limited antiproliferative effects and absence of apoptosis associated with persistent activity of extracellular signal-regulated kinase or Akt kinase pathways. Clin Cancer Res. 2003; 9: 2316-26. doi:

13. Sos ML, Koker M, Weir BA, Heynck S, Rabinovsky R, Zander T, Seeger JM, Weiss J, Fischer F, Frommolt P, Michel K, Peifer M, Mermel C, et al. PTEN loss contributes to erlotinib resistance in EGFR-mutant lung cancer by activation of Akt and EGFR. Cancer Res. 2009; 69: 325661. doi: 10.1158/0008-5472.CAN-08-4055.

14. Amador ML, Oppenheimer D, Perea S, Maitra A, Cusatis G, Iacobuzio-Donahue C, Baker SD, Ashfaq R, Takimoto C, Forastiere A, Hidalgo M. An epidermal growth factor receptor intron 1 polymorphism mediates response to epidermal growth factor receptor inhibitors. Cancer Res. 2004; 64: 9139-43. doi: 10.1158/0008-5472.CAN-04-1036.

15. Liu G, Cheng D, Ding K, Le Maitre A, Liu N, Patel D, Chen Z, Seymour L, Shepherd FA, Tsao MS. Pharmacogenetic analysis of BR.21, a placebo-controlled randomized phase III clinical trial of erlotinib in advanced non-small cell lung cancer. J Thorac Oncol. 2012; 7: 316-22. doi: 10.1097/ JTO.0b013e31824166c1.

16. Liu G, Gurubhagavatula S, Zhou W, Wang Z, Yeap BY, Asomaning K, Su L, Heist R, Lynch TJ, Christiani DC. Epidermal growth factor receptor polymorphisms and clinical outcomes in non-small-cell lung cancer patients treated with gefitinib. Pharmacogenomics J. 2008; 8: 12938. doi: 10.1038/sj.tpj.6500444.

17. Gridelli C, Ciardiello F, Gallo C, Feld R, Butts C, Gebbia V, Maione P, Morgillo F, Genestreti G, Favaretto A, Leighl N, Wierzbicki R, Cinieri S, et al. First-line erlotinib followed by second-line cisplatin-gemcitabine chemotherapy in advanced non-small-cell lung cancer: the TORCH randomized trial. J Clin Oncol. 2012; 30: 3002-11. doi: 10.1200/JCO.2011.41.2056.

18. Ohashi K, Maruvka YE, Michor F, Pao W. Epidermal growth factor receptor tyrosine kinase inhibitor-resistant disease. J Clin Oncol. 2013; 31: 1070-80. doi: 10.1200/ JCO.2012.43.3912.

19. Stewart EL, Tan SZ, Liu G, Tsao MS. Known and putative mechanisms of resistance to EGFR targeted therapies in NSCLC patients with EGFR mutations-a review. Transl Lung Cancer Res. 2015; 4: 67-81. doi: 10.3978/j.issn.22186751.2014.11.06.

20. Douillard JY, Shepherd FA, Hirsh V, Mok T, Socinski MA, Gervais R, Liao ML, Bischoff H, Reck M, Sellers MV, Watkins CL, Speake G, Armour AA, et al. Molecular predictors of outcome with gefitinib and docetaxel in previously treated non-small-cell lung cancer: data from the randomized phase III INTEREST trial. J Clin Oncol. 2010; 28: 744-52. doi: 10.1200/JCO.2009.24.3030.
21. Hirsch FR, Varella-Garcia M, Bunn PA Jr, Franklin WA, Dziadziuszko R, Thatcher N, Chang A, Parikh P, Pereira JR, Ciuleanu T, von Pawel J, Watkins C, Flannery A, et al. Molecular predictors of outcome with gefitinib in a phase III placebo-controlled study in advanced non-small-cell lung cancer. J Clin Oncol. 2006; 24: 5034-42. doi: 10.1200/ JCO.2006.06.3958.

22. Tsao MS, Sakurada A, Cutz JC, Zhu CQ, Kamel-Reid S, Squire J, Lorimer I, Zhang T, Liu N, Daneshmand M, Marrano P, da Cunha Santos G, Lagarde A, et al. Erlotinib in lung cancer - molecular and clinical predictors of outcome. N Engl J Med. 2005; 353: 133-44. doi: 10.1056/ NEJMoa050736.

23. Fukuoka M, Wu YL, Thongprasert S, Sunpaweravong P, Leong SS, Sriuranpong V, Chao TY, Nakagawa K, Chu DT, Saijo N, Duffield EL, Rukazenkov Y, Speake G, et al. Biomarker analyses and final overall survival results from a phase III, randomized, open-label, first-line study of gefitinib versus carboplatin/paclitaxel in clinically selected patients with advanced non-small-cell lung cancer in Asia (IPASS). J Clin Oncol. 2011; 29: 2866-74. doi: 10.1200/ JCO.2010.33.4235.

24. Rudin CM, Liu W, Desai A, Karrison T, Jiang X, Janisch L, Das S, Ramirez J, Poonkuzhali B, Schuetz E, Fackenthal DL, Chen P, Armstrong DK, et al. Pharmacogenomic and pharmacokinetic determinants of erlotinib toxicity. J Clin Oncol. 2008; 26: 1119-27. doi: 10.1200/JCO.2007.13.1128.

25. Zhu CQ, da Cunha Santos G, Ding K, Sakurada A, Cutz JC, Liu N, Zhang T, Marrano P, Whitehead M, Squire JA, Kamel-Reid S, Seymour L, Shepherd FA, et al. Role of KRAS and EGFR as biomarkers of response to erlotinib in National Cancer Institute of Canada Clinical Trials Group Study BR.21. J Clin Oncol. 2008; 26: 4268-75. doi: 10.1200/JCO.2007.14.8924.

26. Koeppen H, Yu W, Zha J, Pandita A, Penuel E, Rangell L, Raja R, Mohan S, Patel R, Desai R, Fu L, Do A, Parab V, et al. Biomarker analyses from a placebo-controlled phase II study evaluating erlotinib+/-onartuzumab in advanced non-small cell lung cancer: MET expression levels are predictive of patient benefit. Clin Cancer Res. 2014; 20: 4488-98. doi: 10.1158/1078-0432.CCR-13-1836.

27. Yanagawa N, Leduc C, Kohler D, Saieg MA, John T, Sykes J, Yoshimoto M, Pintilie M, Squire J, Shepherd FA, Tsao MS. Loss of phosphatase and tensin homolog protein expression is an independent poor prognostic marker in lung adenocarcinoma. J Thorac Oncol. 2012; 7: 1513-21. doi: 10.1097/JTO.0b013e3182641d4f. 